\title{
The thermal performance of green roofs in a hot, humid microclimate
}

\author{
U. D’Souza \\ F-o-CUS: Focus on Construction Urbanism Sustainability, UAE
}

\begin{abstract}
Green roof applications can alleviate the heat island effect in cities and positively contribute to sustainable development by regulating building temperatures and enhancing its impact and effectiveness on the built environment. Green roofs are an innovative concept for the planning and development of future cities. The aim of this research paper is to review evidence of the environmental impact of using green roofs when compared to a conventional roof in the hot and humid microclimate of the United Arab Emirates (UAE). In order to achieve this, a micro-scale urban ENVI-met model of the Dubai Marina is tested. The parameters measured in this experiment include Surface Albedo (SA), Mean Radiant Temperature (MRT), Relative Humidity (RH) and Predicted Mean Vote (PMV). Improvements in plant to air interaction were also studied using ENVImet simulation software; a three-dimensional microclimate model was designed to simulate surface-plant-air interactions in the urban environment. The programme was used in order to gauge the temperature variations of green roofs when compared to using conventional roofs. A study was conducted on June $21^{\text {st }}$, 2011 at 1:00 pm and December 21 $1^{\text {st }}$, 2011 at 1:00 pm which depicted variations in temperature due to the impact of green roofs between these two different periods. During the hot, humid months SA and PMV were the predominant changes documented due to the impact of green roofs. However, during the winter months temperature changes such as, MRT and RH were clearly visible in the ENVI-met simulations. The research revealed findings to suggest that a green roof can contribute to a significant improvement in the thermal comfort levels of the surrounding built environment. These findings can be used by the relevant stakeholders, planners, architects, engineers and developers to recommend green roofs as a necessity for the sustainable development of future cities.

Keywords: thermal performance, green roofs, hot, humid micro-climate, sustainable development, planning, sustainable architecture, built environment and heat island.
\end{abstract}




\section{Introduction}

Densely populated urban area in the Dubai microclimate is characterized by numerous buildings, infrastructure and hard scapes that absorb heat rapidly leaving massive hot spots also known as heat islands. In an effort to alleviate heat levels in the region, the Dubai municipal government adopted a green building initiative in 2008. This initiative encouraged the use of green roofs on buildings because of the positive impact on cooling hot and humid areas, reducing carbon emissions and controlling energy consumption levels within buildings, all leading to an energy savings solution for sustainable development.

A high land value in urban areas has led to an immediate need for green space alternatives. Several environmental benefits include; promoting biodiversity, reducing air pollution and dust, absorbing solar radiation by the provision of reflective materials, creating attractive open spaces, providing a habitat for wildlife, opening more doors for re-using and recycling building materials. This research will explore the performance of green roofs in the hot and humid microclimate. It will assess the research covered by past academics and by using simulation software ENVI-met evaluate a conventional roof model in comparison to a green roof model under UAE microclimatic conditions and then formulate results and encourage discussion based on the modelled scenario.

\section{UAE climate}

According to climate data from National Centre of Meteorology and Seismology in the UAE (NCMS) [1], the temperature ranges of hot and humid summer months reaches a high of $48^{\circ} \mathrm{C}\left(118.4^{\circ} \mathrm{F}\right)$ to the warm winter months dropping to a minimum of $14^{\circ} \mathrm{C}\left(50^{\circ} \mathrm{F}\right.$ and $\left.57.2^{\circ} \mathrm{F}\right)$. Humid south-eastern winds (sharqi) dominate the coastal region during the summer, whereas cool north-westerly winds (shamal) develop during the winter months. Humidity is high during the summer, reaching over $90 \%$, but it declines to $50-60 \%$ in the coastal regions during the winter NCMS [1]. Rainfall is limited, arriving in short sharp bursts during the winter months. Thunder and dust storms occur during the summer accompanied by severe flash floods over the south-eastern mountains. The region is characterised by a regular formation of dew that assists in the survival of plants and wildlife.

\section{Green roof research through observation}

Green roofs can help regulate the urban microclimate and minimize the occurrence of heat islands [2-5]. Based on prior research experiments in hot and humid climates, the following parameters Surface Albedo (SA), Mean Radiant Temperature (MRT) and Relative Humidity (RH) have been observed.

Surface Albedo (SA) determines the solar reflectivity on a surface. According to Taha [6], albedo levels for most cities range from 0.10 to 0.20 . North African towns are considered a good example of SA ranging from $0.30-0.45$. Extensive the vegetation in towns lead to a higher the SA. A mesoscale simulation model 
developed by Taha [6] found that SA in Los Angeles, USA can result in a $2^{\circ} \mathrm{C}$ temperature decrease. This decrease suggested lower electricity consumption by $10 \%$ by air conditioning. Sailor [4] simulated the effects of albedo in the Florida, USA urban environment and found that a higher in albedo using vegetation can result in a $2^{\circ} \mathrm{C}$ decrease in air temperature while extreme increase in albedo can result in a $4^{\circ} \mathrm{C}$ temperature reduction. It was deduced that $\mathrm{SA}$ can aid temperature reduction in cities.

Mean Radiant Temperature (MRT) is calculated based on ambient air temperatures, global temperatures and air velocity. Wong et al. [7] measured the MRT in Singapore above hard surfaces and vegetated surfaces and found that solar radiation exposure on hard surfaces during the day emitted more long-wave radiation to the surrounding environment at night leading to uncomfortable thermal comfort levels. MRT measured for vegetated roofs confirmed a reduced long-wave radiation emission regulated by plants and absorbed to the roof surface. Kakon and Nobou [8] studied the effects of MRT on a modelled canyon in Dhaka, Bangladesh and found that levels vary during the day depending on air flow movements affected by surrounding built environment such as, building heights, vegetation, climate, sky view factor (SVF) and global temperatures. Air flow can also regulate humidity levels in the urban areas.

Humidity levels in Singapore studied by Wong et al. [9] on hard surfaces and vegetated surfaces were around the same levels. Kakon and Nobou [8] found that Relative Humidity (RH) levels in an urban canyon in Dhaka, Bangladesh were higher during the day especially in places with a higher sky view factor (SVF). Higher SVF resulted in higher air temperatures (Ta) causing higher RH levels because of the amount of solar radiation absorbed. Increased building heights and tree canopies decreased the SVF resulting in lower Ta and RH levels. Air flow can impact RH levels on urban environments.

Knowledge gaps from these studies include consistent simulated temperature profiles that can validate the research of thermal performance of green roofs in the UAE. An investigation on a local site study of Dubai, UAE in section 7 will involve a discussion on the results of the green roof thermal performance levels.

\section{Green roof research through ENVI-met simulation}

ENVI-met micro-climatic numerical modelling software was developed by Michael Bruse and designed to assess conditions in urban developments. It has the capacity to easily translate numerical data founded on the fundamental laws of fluid dynamics and thermo-dynamics to simulate surface, vegetation and atmospheric exchanges within the urban environment. ENVI-met software validity falls under the scrutiny of several scientific entities, government organisations and researchers. Previous studies [10-12] found limitations in the software flexibility required to create the urban environment. However, a conceptual surface can be suggested. Evidence of such is apparent in the research literature conducted by Bruse [10], which validate the ENVI-met results. 


\section{Site in context}

Dubai is located in UAE north (see figure 1). The Dubai Marina Master Plan (see figure 2) was developed by architectural firm HOK comprising of a total land area of approximately 578 ha NRI [13]. The initial concept is based on a 'city within a city' model which houses a waterfront community development consistent of luxury apartments, condominiums and villas. The Dubai Marina not only serves a high density residential community, it encompasses offices and retail facilities making it a pedestrian friendly environment.

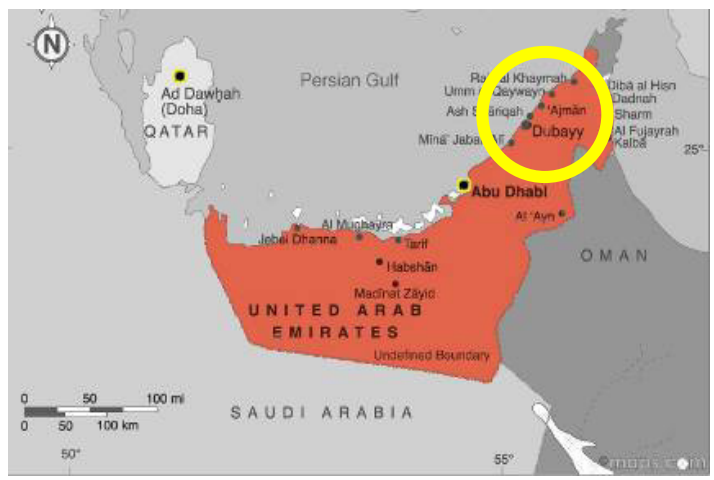

Figure 1: $\quad$ Location of Dubai (Maps 2011).

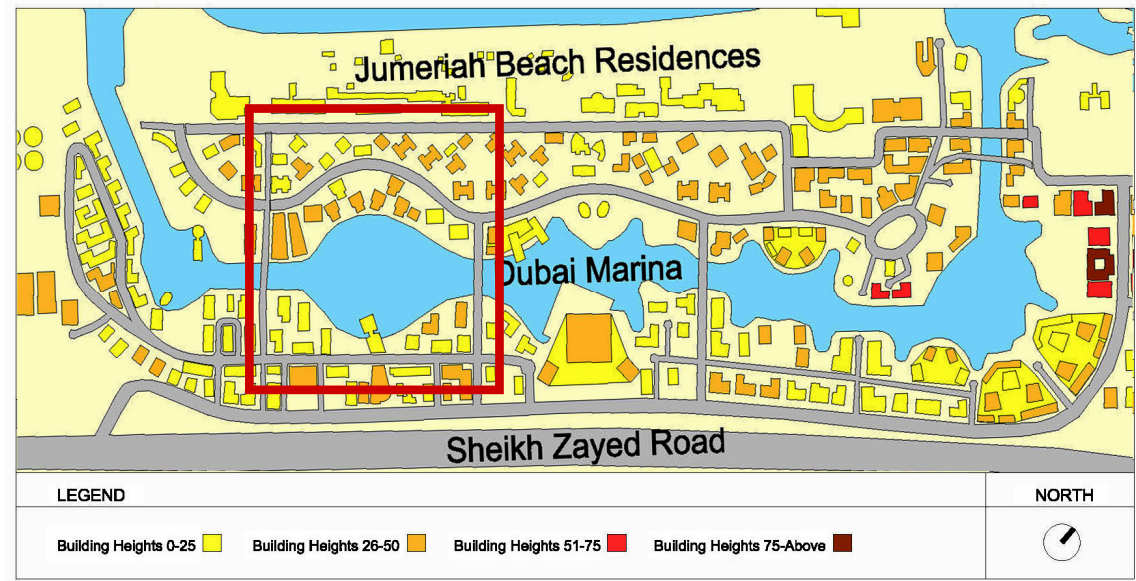

Figure 2: $\quad$ Site area and density on AutoCAD. 


\section{Modelling the context with ENVI-met}

Modelling the Dubai Marina context on June $21^{\text {st }}$, 2011 at 1:00 pm and December $21^{\text {st }}$, 2011 at 1:00 pm using ENVI-met involves a calculation of fluid dynamics and thermodynamic processes at surfaces/walls/roofs and plants Bruse [10]. The four processes are defined below:

\section{- Model area inputs}

According to Bruse [10], this is based on the model size, location, dimension and building environment. Building heights, soil types, plants and surface conditions can be defined in the area input editor.

\section{- Model configuration}

Including a model configuration file can help the model run an analysis for that period to test the thermal comfort levels. In this case the measured performance parameters include humidity, temperature and Surface Albedo.

- $\quad$ Model run and outputs

Model is tested and run following the assigned time frame (June $21^{\text {st }}$, 2011 at 1:00 pm and December $21^{\text {st }}, 2011$ at 1:00 pm because of variations in temperature due to the suns angle during the two periods) input into the configuration while generating the necessary output field for the tested parameters specified in the model configuration.

\section{- $\quad$ LEONARDO visualisation}

LEONARDO visualises the output files generated from the model run. This is based on the selected time frame, outputs and area recorded.

The simulation date is set during the summer solstice June $21^{\text {st }}, 2011$ and the winter solstice December $21^{\text {st }}, 2011$. The sun is at peak intensity on June $21^{\text {st }}$. During the winter period, the sun is at a lower angle. Seasonal variation is tested to validate thermal performance levels purely because during winter months, the earth surface does not receive as much solar energy from the sun in the Northern hemisphere when compared to the summer months.

\section{Results and discussion}

ENVI-met documented results of the numeric simulation tests done to measure the thermal performance levels of a conventional roof and a green roof by programming the inputs into the two models on a built up section of the Dubai Marina on June $21^{\mathrm{st}}, 2011$ at 1:00 pm and December $21^{\mathrm{st}}, 2011$ at 1:00 pm. The major difference between the two models included different inputs programmed in the base and green roof model along with the location and building details. In the green roof scenario, additional inputs such as plant and soil typology were programmed based on the ENVI-met database selection available. A comparison of these changes is documented in the tables of the following four parameters. 


\section{Parameter 1: Surface Albedo (SA)}

A Surface Albedo (SA) assessment was conducted using ENVI-met to measure the difference in albedo levels during the summer period for the base and green roof scenario. In doing so the simulation was run and the derived edi. file was taken to the LEONARDO to define the results. By including green roofs in the Dubai Marina ENVI-met sectional model, the SA increased from a low of $0.12-0.16$ in the summer and winter conventional roof model to $0.16-0.20$ in the summer and winter green roof model (see figure 3).

There is no major difference in the SA increase as the tested inputs did not yield significant changes. This could be due to several factors which influence the SA of green roofs, such as the type of plants used for the roof and the materials used in installation. A rise in SA rise represents the potential for green roofs to reduce surface temperature and long wave radiation emitted from the roof surface.

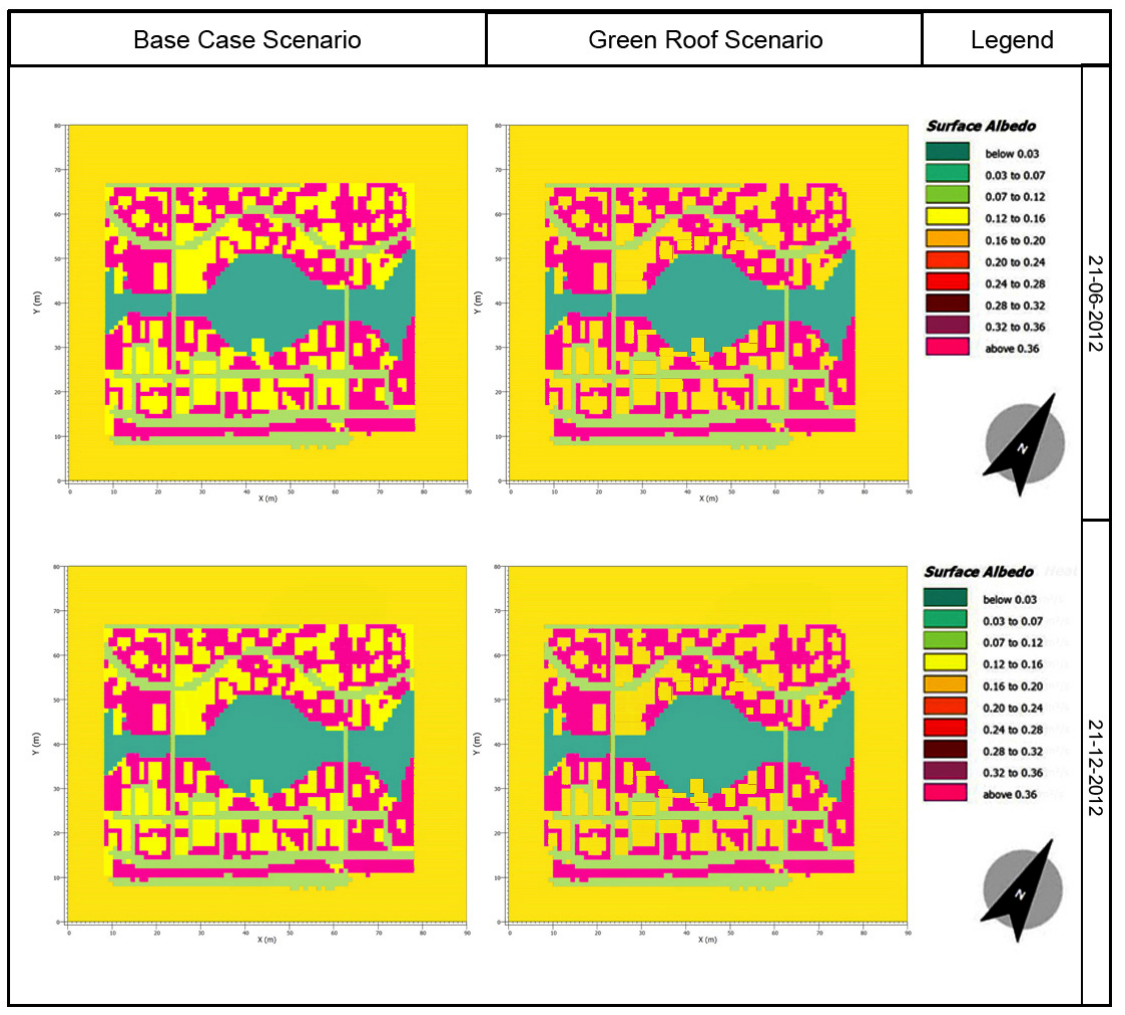

Figure 3: $\quad$ ENVI-met Surface Albedo (SA) results of base and green roof. 


\section{Parameter 2: Mean Radiant Temperature (MRT)}

A Mean Radiant Temperature analysis was conducted using ENVI-met to measure the difference in levels during the summer period for the base and green roof scenario. The Mean Radiant Temperature (MRT) in the summer time ENVI-met simulation remains between $49.62^{\circ} \mathrm{C}-51.73^{\circ} \mathrm{C}$ in the base roof and green roof scenario. The winter time base roof and green roof scenario was measured at $36.91^{\circ} \mathrm{C}-39.03^{\circ} \mathrm{C}$ when compared to the summer time MRT from $49.62^{\circ} \mathrm{C}-51.73^{\circ} \mathrm{C}$ (see figure 4 ).

There is not much change in temperature when compared to the base case winter time roof scenario. Changes in MRT can occur due to green roof installation typology as green roof soft surface emits less long wave radiation when compared to hard surfaces such as in the base roof. Leaf foliage and density can also affect MRT and therefore temperature variations can depend on the inputs programmed. At present the plant inputs were limited to the ENVI-met database selection.

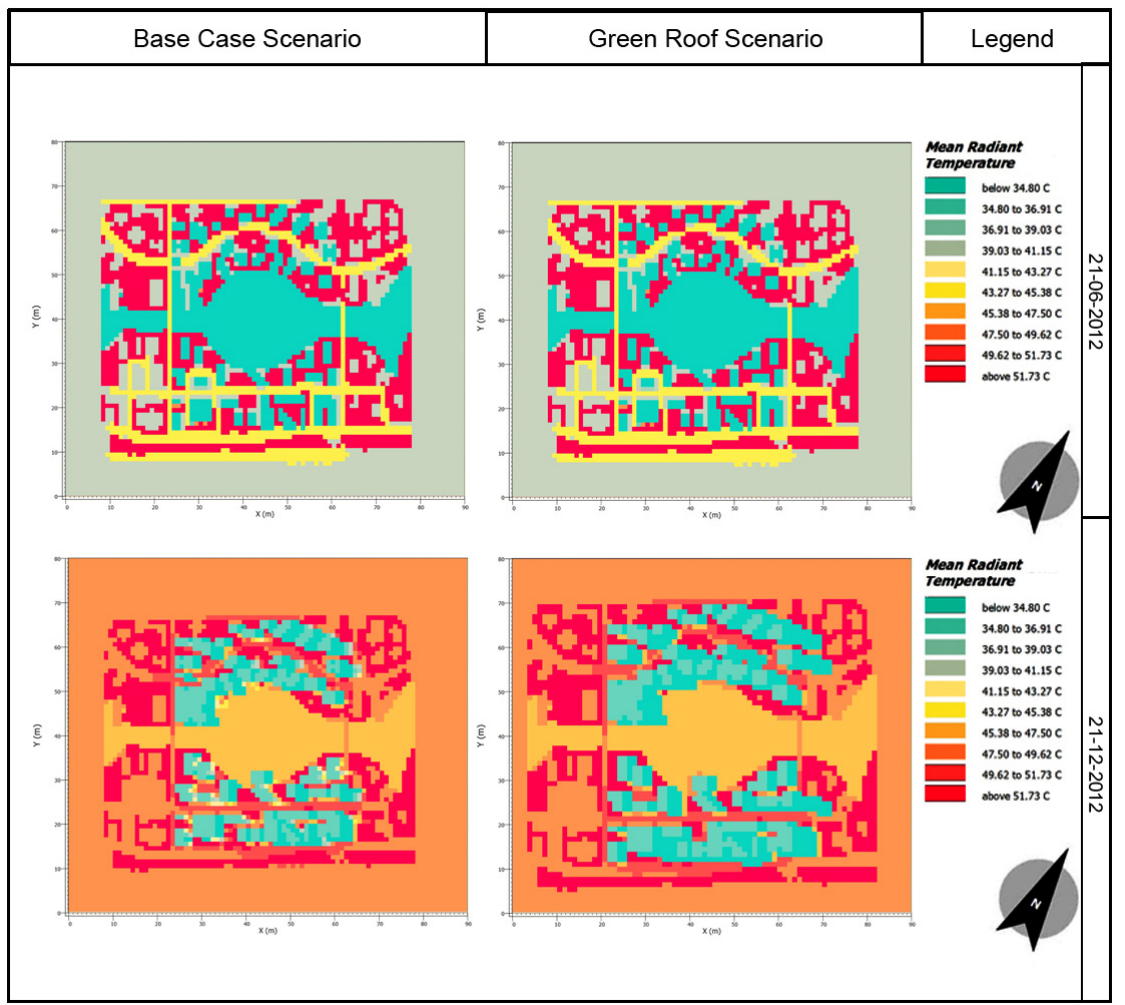

Figure 4: $\quad$ ENVI-met Mean Radiant Temperature (MRT) results of base and green roof. 


\section{Parameter 3: Relative Humidity (RH)}

A Relative Humidity (RH) study was conducted using ENVI-met to measure the difference in $\mathrm{RH}$ levels during the summer period for the base and green roof scenarios. In doing so the ENVI-met simulation was run for all four models and once the edi. file was derived; it was taken to the LEONARDO program to define the results. The $\mathrm{RH}$ study (see figure 5) reveal values at a range of $83.44 \%$ to $86.87 \%$ during summer base case and green roof scenario.

$\mathrm{RH}$ is recorded above $108.05 \%$ during the winter, slightly higher when compared to the winter base case conventional roof scenario. The average RH was measured at $85 \%$ in a dense urban context at 13:00 hours. Since there was no change yielded in $\mathrm{RH}$ between the base roof and green roof in both seasons during the ENVI-met experiment, it is recommended that further research be conducted on soil and substrate depth and its influence on RH.

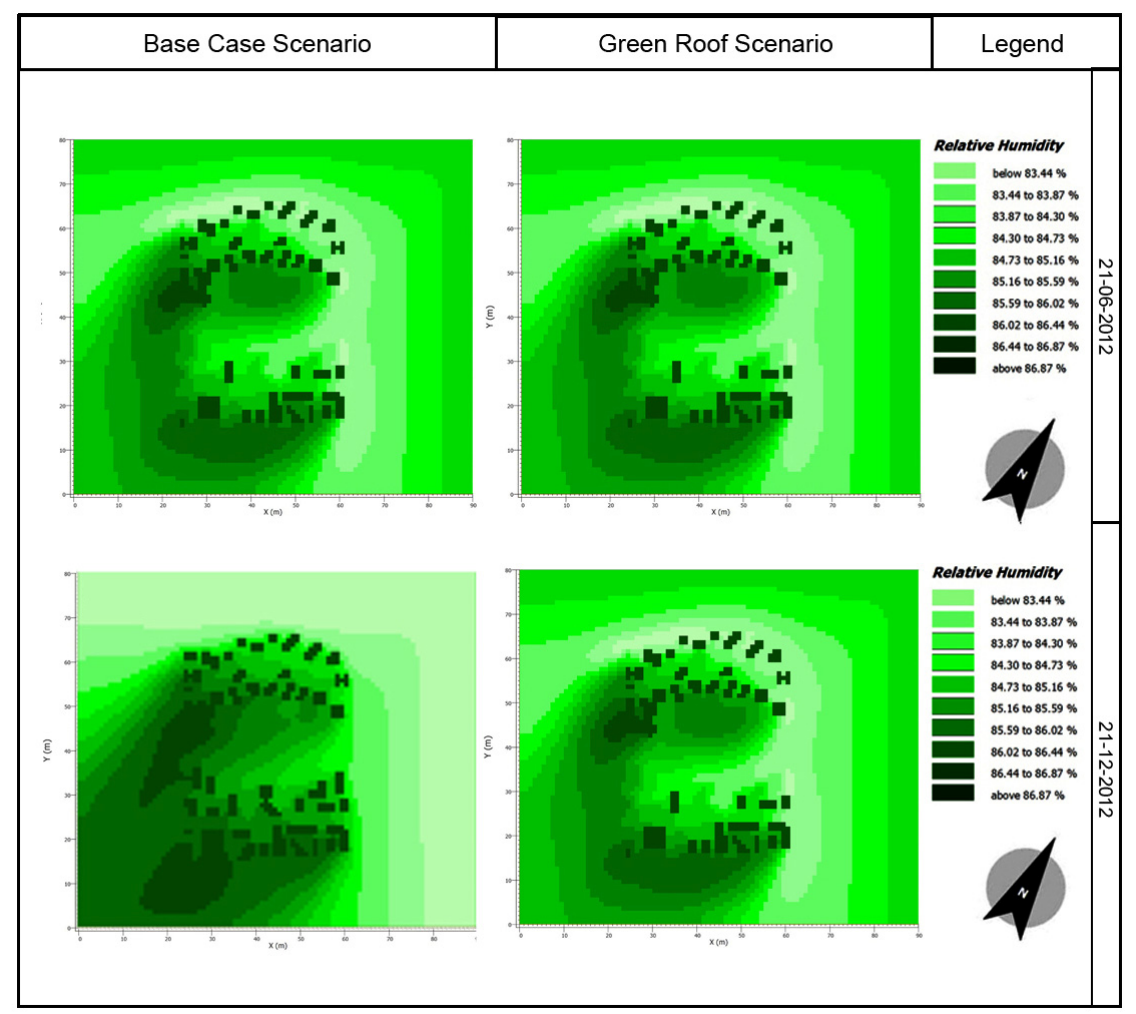

Figure 5: $\quad$ ENVI-met Relative Humidity $(\mathrm{RH})$ results of base and green roof. 


\section{Parameter 4: Predicted Mean Vote (PMV)}

The Predicted Mean Vote (PMV) simulated by ENVI-met depicts a slight change in PMV numbers from the summer base case and green roof scenarios (See figure 6). This slight change is represented by a change from -0.51 to -0.35 in the base case scenario to -0.01 to 0.33 in the green roof scenario. As this satisfies the ANSI/ASHRAE Standard 55 [14, 15] and ISO 7730 [16] of human thermal comfort range -0.5 to +0.5 (neutral) the level of thermal sensations experienced by an individual is minor when measured on a small section of the Dubai Marina (refer to section 5, figure 2), but this could be due to the nature of plants assumed. A large area when tested may suggest different results.

Consequently, the ENVI-met green roof modelled during the winter measured PMV at -1.15 to -0.16 which resulted in a slight change in PMV numbers from the base case winter roof scenario measured at -1.48 to -0.82 . When compared to summer green roof measured at -0.01 to 0.33 , the winter PMV range is cooler. $\mathrm{PMV}$ is found to be cooler in winter due to the UAE experiencing warm/cool winter months and the north-westerly shamal winds.

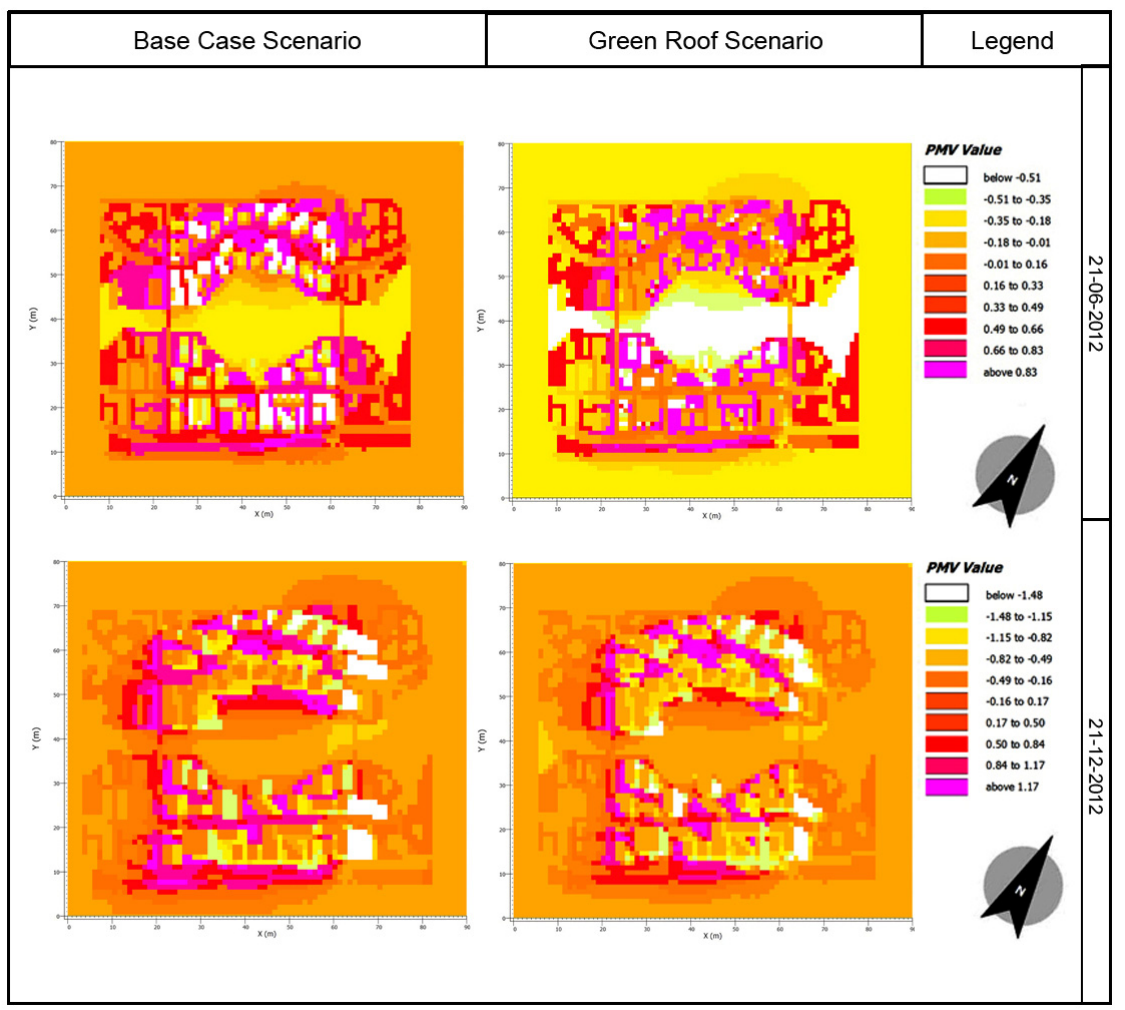

Figure 6: ENVI-met Predicted Mean Vote (PMV) results of base and green roof. 
Climatic factors such as Mean Radiant Temperature (MRT) and Relative Humidity $(\mathrm{RH})$ were found to be consistent in both simulation scenarios, one possibility is because the green roof inputs were simply normalised ENVI-met inputs and variation in plant selection or foliage density could result in a change of either of the above parameters. Green roofs also provide protection to the roof membrane from incoming solar radiation and so although the Mean Radiant Temperature (MRT) value does not change, green roofs can moderate both the long wave radiation emitted and the heat transfer coefficient. By protecting the roof membrane from long wave radiation, green roofs provide an effective insulation barrier which can reduce indoor cooling loads and regulate energy consumption. The Predicted Mean Vote (PMV) recorded an improved levels in thermal comfort compared to that of the base roof, these changes were not significant and were still considered in the neutral range satisfying the ANSI/ASHRAE Standard 55 [14, 15] and ISO 7730 [16]. However, it gives an indication that planted roofs could effectively mitigate the Urban Heat Island (UHI) effect in an urban environment.

\section{Conclusions}

The thermal implications of using green roofs in the built environment as the main aim of this study involve testing the introduction of vegetation in a hot and humid climate through investigation of previous research and ENVI-met simulation. The ENVI-met study was undertaken to observe the impact of green roofs in the hot and humid micro-climate of the Dubai Marina development. It is recommended that the outdoor thermal implications of this study are essential for developers, architects and engineers to progress towards innovative strategies for heat island mitigation.

- In the hot and humid Dubai climate adding vegetation to roofs has been shown to raise Surface Albedo (SA). Experimentation by Taha [6] and Sailor [4] concluded that vegetation can result in higher albedos. The SA rise recorded in the ENVI-met study is considerable but still not considered a significant increase. The slight SA increase has resulted in reduced surface temperatures. Further increase in SA can be accomplished depending on the type of vegetation selected. Vegetation that meets the minimal water requirements and is climate specific is ideal for any green roof scenario.

- When measuring Mean Radiant Temperature (MRT) on a vegetated roof long wave radiation was significantly reduced compared to a conventional roof and consistent with similar findings by Wong et al. [7] and Kakon and Nobou [8]. The ENVI-met simulation on the Dubai Marina confirmed changes in MRT in the winter months when compared to summer months. This is a consequence of a climatic condition such as a lower sun angle in the winter when compared to summer.

- Relative Humidity (RH) levels in the ENVI-met simulation study on the Dubai Marina found to have decreased levels in the summer when compared to that depicted in the winter. The change could be the result of higher wind 
temperatures during winter months and consistent with those results founded by Wong et al. [9] and Kakon and Nobou [8] on the influence of building heights and air flow on RH. However, RH on green roofs changed very little from those levels found on the conventional roof in both winter and summer scenarios. Again this could be because of the efficient variation of building heights in the Dubai Marina regulating air flow movements.

- According to ANSI/ASHRAE Standard $55[14,15]$ and ISO 7730 [16] of human thermal comfort for Predicted Mean Vote (PMV) ranges between -0.5 to +0.5 (neutral). Consequently, the ENVI-met green roof model for December $21^{\text {st }} 2011$ measured PMV at -1.15 to -0.16 which resulted in a slight change in PMV numbers from the base case winter roof scenario which was measured at -1.48 to -0.82 . Compared to the summer time green roof measured at -0.01 to 0.33 , the winter time PMV range is cooler.

Finally, limitations of the ENVI-met software do not allow for a detailed assessment of plant and substrate details to influence all the parameters discussed above. However, ENVI-met does provide a general analysis through a conceptual model of the potential impacts of using green roofs and the potential benefits of that application. The outcome of the results provided through the numeric ENVI-met model show that there is evidence to suggest that green roof applications can effectively increase SA, reduced surfaces temperatures and improve outdoor thermal comfort as studied through PMV. Climatic conditions and urban planning practices studied in ENVI-met support the development of the green roof in a hot and humid micro-climate, however, possible monitoring of large scale sites, developments with different densities and available technical solutions for green roof systems such as layers, materials, plants, and soil thickness can also be observed. In order to deduce quantitative results the parameters will have be standardised to suit previous research findings and can be recommended for further research to determine the similarities and differences of possible outcomes. Furthermore, a more specific technical objective can then be suggested based on the quality of green roof performance and the involved components of the system. This can then be developed as a successful dialogue to address the design and planning of green roofs for sustainable development and construction.

\section{Acknowledgements}

Dr Hanan Taleb, Faculty of Engineering and IT at The British University in Dubai, UAE and Welsh School of Architecture, Cardiff University, UK.

\section{References}

[1] National Centre of Meteorology and Seismology in the UAE. [Online] http://www.ncms.ae/english/ 2010.

[2] Dubai Municipality, Green Roof Manual: Guidelines for Planning, Execution \& Maintenance of Green Roof Various Applications. Dubai 
Municipality, Government of Dubai, UAE. [Online] pp. 1-46 www.dm.gov.ae 2009.

[3] Dubai Municipality, Dubai Green Building Regulations. Dubai Municipality, Government of Dubai, UAE. [Online] pp. 1-46 www.dm.gov.ae 2010.

[4] Sailor, D.J., A green roof model for building energy simulation programs. Energy and Buildings. Vol. 40 (8), pp. 1466-1478, 2008.

[5] Shashua-Bar, L. and Hoffman, M., (2004). Quantitative evaluation of passive cooling of the UCL microclimate in hot regions in summer, case study: Urban streets and courtyards with tress. Building and Environment. Vol. 39 (9), pp. 1087-1099, 2004.

[6] Taha, H., Urban climates and heat islands: albedo, evapotranspiration, and anthropogenic heat. Energy and Buildings, Oxford, vol. 25 (2), pp. 99-103, 1997.

[7] Wong, N., Cheong, D., Yan, H., Soh, J., Ong, C., and Sia, A., The effects of rooftop garden on energy consumption of a commercial building in Singapore. Energy and Buildings, Vol. 35 (4), pp. 353-364, 2003b.

[8] Kakon, A.N., and Nobuo, M., The sky view factor effect on the microclimate of a city environment: A case study of Dhaka City. Proceedings of the 7th International Conference on Urban Climate, June 29-July 3, Yokohama, Japan, pp.: 1-4, 2009.

[9] Wong, N., Chena, Y., Ong, C. and Siab, A., Investigation of thermal benefits of rooftop garden in the tropical environment. Buildings and Environment. Vol. 38 (1), pp. 261-270, 2003a.

[10] Bruse, M., Modelling and Strategies for Improved Urban Climates. [Online] http://www.envi-met.com/documents/papers/strategies1999pdf 1999.

[11] Okeil, A., A holistic approach to energy efficient building forms. Energy and Buildings. Vol. 42 (9), pp. 1437-1444, 2010.

[12] UAEInteract, UN Conference on Trade and Development (UNCTAD). [Online] www.uaeinteract.com/docs/UAE_population 2010.

[13] NRI, Dubai Marina, Dubai, U.A.E. [Online] Net Resources International http://www.designbuild-network.com/projects/dubai-marina/ 2011.

[14] American Society of Heating Refrigerating and Air Conditioning Engineers (ASHRAE). Thermal Environmental Conditions for Human Occupancy. (ASHRAE Standard 55-1992). Atlanta, GA. 1992.

[15] American Society of Heating Refrigerating and Air Conditioning Engineers (ASHRAE). Thermal Comfort. ASHRAE Handbook: Fundamentals (p. 8.18.29). Atlanta, GA. 2001.

[16] ISO Standard 7730, Moderate Thermal Environments Determination of the PMV and PPD Indices and Specifications of the Conditions for Thermal Comfort. International Standards Organizations, pp. 1-26, 1994. 